\title{
Energy-saving technology for water hydraulic motor system (First report: simulation result)
}

\author{
Pha N. PHAM ${ }^{* * *}$ and Kazuhisa ITO** \\ * Department of Machinery Engineering, Hanoi University of Science and Technology \\ 1 Dai Co Viet Road, Hanoi, Vietnam \\ ** Department of Machinery and Control Systems, Shibaura Institute of Technology \\ 307 Fukasaku, Minuma-ku, Saitama, 337-8570, Japan \\ E-mail: phamngocpha@gmail.com
}

Received 30 June 2016

\begin{abstract}
Recently, the application of water hydraulics has received considerable attention because of its inherent merits such as environmental friendliness, hygiene, washability, high safety against fire hazard, lower running cost, and availability of tap water. However, water hydraulic systems have lower energy efficiencies than oil hydraulic systems, and this prevents its wider application. The water hydraulic variable displacement pump is yet to be made available in the market as it requires advanced technology and high manufacturing cost. Currently, water hydraulic servo/proportional valve systems or independent metering systems incorporating fixed displacement pumps lose large amounts of energy because of surplus pressure and flow rate. This study is aimed at designing a novel water hydraulic transmission technique to improve the efficiency of motor systems. The proposed system uses two two-way, two-position flow control valves for controlling the pressure at the input port of the hydraulic motor by releasing small amounts of surplus flow rate to a reservoir through these valves. The surplus pressure in such systems can be minimized and made equal to the hose pressure drop. The simulation results showed that the proposed transmission system can improve the energy efficiency of the independent metering system and conventional system to approximately twice and thrice the current value, respectively. In this study, the energy losses in the three systems were also analyzed in detail.
\end{abstract}

Key words : Water hydraulics, Energy-saving, Servo motor system, Independent metering system, Velocity response

\section{Nomenclature}

$A_{\text {On/Off }} \quad$ Opening area of On/Off valve $\left[\mathrm{m}^{2}\right]$

$b_{l} \quad$ Left break-point of the dead-zone [m]

$b_{r} \quad$ Right break-point of the dead-zone [m]

$C_{L i} \quad$ Internal leakage flow coefficient $\left[\mathrm{m}^{3} /(\mathrm{sPa})\right]$

$D_{m} \quad$ Displacement of the motor $\mathrm{M}\left[\mathrm{m}^{3} / \mathrm{rev}\right]$

$e(t) \quad$ Tracking error $[\mathrm{rad} / \mathrm{s}]$

$E \quad$ Bulk modulus of water [Pa]

$E_{r} \quad$ Required energy [J]

$E_{s} \quad$ Supply energy [J]

$I_{F W} \quad$ Moment of inertia of flywheel $\left[\mathrm{kgm}^{2}\right]$

$k_{v} \quad$ Gain of servo valve [ - ]

$K_{q A} \quad$ Flow gain coefficient of the orifice A [ - ]

$K_{q B} \quad$ Flow gain coefficient of the orifice B [ - ]

$P_{A} \quad$ Pressure at the port A of the servo valve [Pa]
$P_{B} \quad$ Pressure at the port $\mathrm{B}$ of the servo valve $[\mathrm{Pa}]$

$P_{L} \quad$ Load pressure [Pa]

$P_{r} \quad$ Reservoir pressure $[\mathrm{Pa}]$

$P_{S} \quad$ Supply pressure $[\mathrm{Pa}]$

$Q_{A} \quad$ Flow rate at the port A of the motor $\mathrm{M}\left[\mathrm{m}^{3} / \mathrm{s}\right]$

$Q_{B} \quad$ Flow rate at the port B of the motor $\mathrm{M}\left[\mathrm{m}^{3} / \mathrm{s}\right]$

$Q_{L} \quad$ Load flow rate $\left[\mathrm{m}^{3} / \mathrm{s}\right]$

$Q_{\text {On/Off }} \quad$ Flow rate through the On/Off valve $\left[\mathrm{m}^{3} / \mathrm{s}\right]$

$Q_{s} \quad$ Supply flow rate $\left[\mathrm{m}^{3} / \mathrm{s}\right]$

$t_{e} \quad$ Ending time of system operation [s]

$t_{s} \quad$ Starting time of system operation [s]

$T_{f} \quad$ Friction torque [Nm]

$T_{m} \quad$ Hydraulic motor torque [Nm]

$V_{0} \quad$ Volume of two chambers of the motor $\mathrm{M}\left[\mathrm{m}^{3}\right]$ 
$x_{v} \quad$ Servo valve spool displacement $[\mathrm{m}]$

$x_{v e} \quad$ Effective servo valve spool displacement [m]

$\alpha_{d} \quad$ Discharge coefficient [ - ]

$\Delta E_{F V 1 \text { or2. }} \quad$ Energy loss over the valve $\mathrm{FV}_{1}$ or $\mathrm{FV}_{2}[\mathrm{~J}]$

$\Delta E_{\text {in. }} \quad$ Energy loss at meter-in orifice [J]

$\Delta E_{\text {out. }} \quad$ Energy loss at meter-out orifice [J]

$\Delta E_{P} \quad$ Energy loss due to surplus pressure [J]

$\Delta E_{p \& u}$. Piping loss and unload On/Off valve loss [J]

$\Delta E_{Q} \quad$ Energy loss due to surplus flow rate [J]
$\Delta E_{R V} \quad$ Energy loss through relief valve [J]

$\triangle P \quad$ Surplus pressure [Pa]

$\Delta P_{\text {On } / \text { Off }}$ Pressure difference over On/Off valve [Pa]

$\Delta Q \quad$ Surplus flow rate $\left[\mathrm{m}^{3} / \mathrm{s}\right]$

$\eta_{m} \quad$ Efficiency of the hydraulic motor [\%]

$\rho \quad$ Mass density of water $\left[\mathrm{kg} / \mathrm{m}^{3}\right]$

$\tau_{v} \quad$ Time constant of the servo valve [ - ]

$\omega \quad$ Flywheel angular velocity $[\mathrm{rad} / \mathrm{s}]$

$\omega_{\text {ref. }} \quad$ Reference angular velocity $[\mathrm{rad} / \mathrm{s}]$

\section{Introduction}

Owing to the outstanding advantages, water hydraulics, which uses pure tap water as the pressure medium has been applied in many fields, especially food (Yoshida, 2015; Sato, 2015), beverages, semiconductors, medicine processing, steel and glass production, ocean exploration, underwater robotics (Yin et al., 2011), nuclear power generation (Minakawa et al., 2013), underwater gait-training orthosis (Kobayashi and Ito, 2013), wave/wind power generation systems, mining machinery, ocean development machinery (e.g., underwater drilling machinery) (Yoshida and Miyakawa, 2013), etc.

On the other hand, energy efficiencies of fluid power systems are low. It varies between $6 \%-40 \%$ depending on the application; the average efficiency is only around 21\% (Stelson, 2011; Wang and Wang, 2014) for oil hydraulics. The energy efficiencies of aqua drive systems are much lower than that of oil hydraulic ones owing to the larger friction and higher amount of leakage in water hydraulic devices, which in turn are due to the low viscosity of pure tap water. In water hydraulic systems, only fixed displacement pumps have been used until now because a water hydraulic variable displacement pump requires advanced technology, which will increase the manufacturing cost. As a result, load-sensing technology, which requires a variable displacement pump, cannot be applied in water hydraulic systems. The energy losses due to the surplus pressure and flow rate degrade the energy efficiency of hydraulic systems.

In traditional hydraulic systems, the two ports of the actuator are controlled by the traditional four-way, three-position servo/proportional valve with one single control signal (Merritt, 1967; Plummer and Vaughan, 1996; Tsao and Tomizuka, 1994; Pham et al., 2013; Ito, 2011; Yao et al., 2000). In this types of valves, the inlet (meter-in) and outlet (meter-out) orifices are mechanically linked together (Liu and Yao, 2008; Xu et al., 2015). Hydraulic systems of this type are easy to control and highly robust, although inefficient. The energy loss through the meter-out orifice is large, especially during the acceleration and constant (velocity) phases of the hydraulic motor, when the meter-out orifice is not required to control the operation. This loss is solely because of the mechanical connection between the meter-in and meter-out orifices.

In traditional oil hydraulic systems, the independent metering system in which the meter-in and meter-out orifices are independently controlled has been studied and applied to improve the energy saving performance. Recently, many studies have been conducted on this category of energy efficient systems (Liu and Yao, 2008; Xu et al., 2015; Nielsen, 2005; Yao and Liu, 2002; Opdensbosch et al., 2013). However, these systems require a variable displacement pump (Xu et al., 2015), which is not suitable for aqua drive systems, or have a complex structure with four or five two-way flow control valves (Xu et al., 2015; Yao and Liu, 2002; Opdensbosch et al., 2013), which leads to a high system cost. Although the system was applied to the independent metering method, it was observed that the pressure drop over the meter-in/meter-out orifice persisted that it was not very small, and that it reduced the energy saving performance.

This study focuses on a novel transmission method for water hydraulic motor systems. Two two-way flow control valves and two On/Off solenoid valves, which were used for changing the rotational direction of the flywheel, were utilized. As a result, the surplus pressure could be minimized; it was equal to the hose loss and small loss through the On/Off valve, which normally was opened fully during operation. By using this method, the energy efficiency of the water hydraulic transmission can rise to be two times and three times of that of the independent metering system and the traditional servo motor system with fixed displacement pump. In this study, detailed analysis of the energy losses in each system was conducted. 


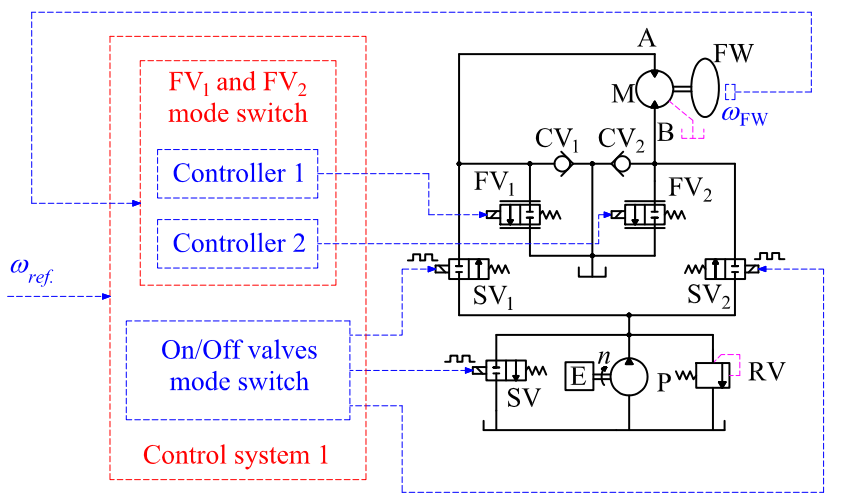

Fig. 1 Proposed water hydraulic circuit for motor system.

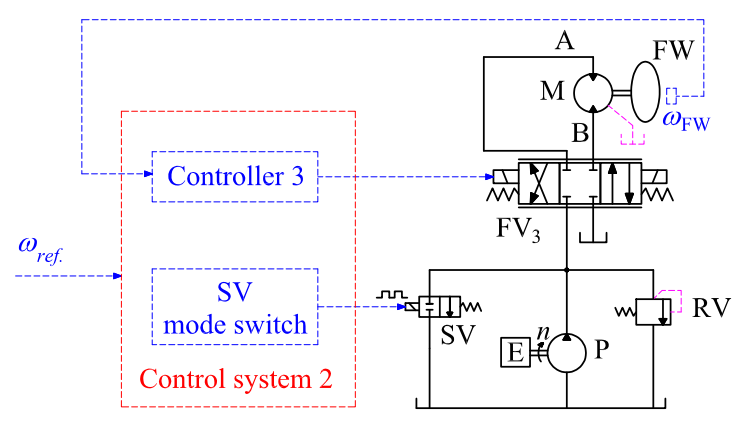

Fig. 2 Conventional water hydraulic servo motor system with unload valve.

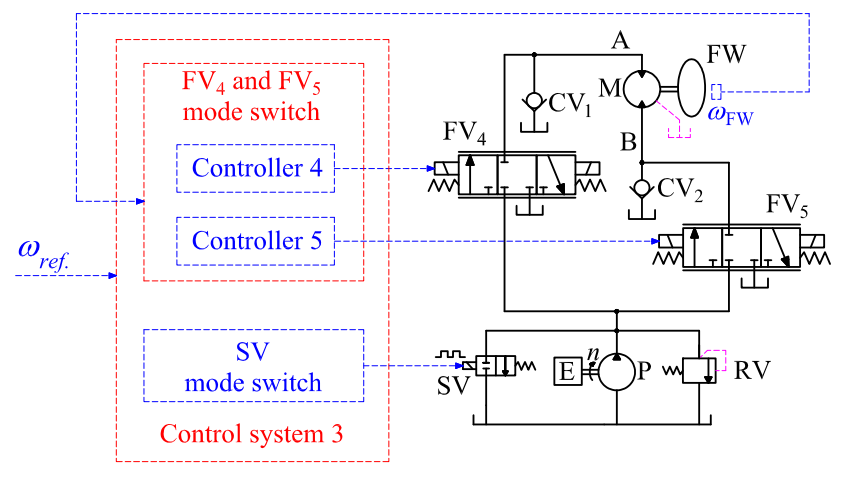

Fig. 3 Independent metering for water hydraulic motor system.

\section{Proposed system and the compared systems}

To examine the influence of the characteristics of the components on the performance of the systems and to evaluate and compare the control performances and energy efficiencies of the proposed system with those of a conventional servo motor system and an independent metering system, a simulator was constructed prior to conducting experiments. This section introduces the proposed water hydraulic circuit for motor systems beside a conventional servo motor system circuit and an independent metering system circuit for comparison. It also describes the mathematical models of important devices in the three systems.

\subsection{System structures}

Figure 1 shows the structure of the proposed system, which includes the following main elements. A fixed displacement pump P is connected to an engine E. A pressure relief valve RV is assembled on the output port of the hydraulic pump $\mathrm{P}$, it is only for safety purpose. A hydraulic motor $\mathrm{M}$ is connected to a flywheel $\mathrm{FW}$, which is considered to be a rotational load on the system. Two solenoid On/Off valves $\mathrm{SV}_{1}$ and $\mathrm{SV}_{2}$ are assembled to form two paths from the pump $\mathrm{P}$ to the motor $\mathrm{M}$ for changing the rotational direction of the flywheel FW. These two paths are connected to two check valves $\mathrm{CV}_{1}$ and $\mathrm{CV}_{2}$, which permit the fluid to flow in only one direction. Two flow rate control valves $\mathrm{FV}_{1}$ and $\mathrm{FV}_{2}$ are branch-connected at one end thereof to check valves $\mathrm{CV}_{1}$ and $\mathrm{CV}_{2}$. These flow control valves are the primary devices for controlling the rotational velocity of the flywheel.

Based on the reference phases as shown in Fig. 5, the operation of the system can be explained as follows. In the first cycle corresponding to the clockwise direction of the flywheel, the valve $\mathrm{VS}_{2}$ is closed. In the acceleration and constant velocity phases, the $\mathrm{On} / \mathrm{Off}$ valve $\mathrm{SV}_{1}$ is opened, the flow control valve $\mathrm{FV}_{2}$ is opened fully and the control valve $\mathrm{FV}_{1}$ is used for controlling the velocity of the flywheel to track the reference. In the deceleration phase, the valve $\mathrm{FV}_{1}$ and the On/Off valve $\mathrm{SV}_{1}$ are closed, the valve $\mathrm{FV}_{2}$ is used for controlling the velocity of the flywheel. Meanwhile, the suction fluid supplied to the motor flows through the check valve $\mathrm{CV}_{1}$. In the second cycle, corresponding to the anticlockwise direction of the flywheel, the operation of the system can be described in the same manner as above, with the only difference that the $\mathrm{On} / \mathrm{Off}$ valve $\mathrm{SV}_{2}$ is opened in the acceleration and constant phases, and the valve $\mathrm{SV}_{1}$ is closed and the functions of the valves $\mathrm{FV}_{1}$ and $\mathrm{FV}_{2}$ are reversed simultaneously. 
Table 1 The specifications of main devices used in simulation.

\begin{tabular}{l|l|l|l}
\hline Devices & Specifications & Values & Units \\
\hline Pump P & Displacement volume & $60 \times 10^{-6}$ & $\mathrm{~m}^{3} / \mathrm{rev}$ \\
\hline Engine E & Rotational velocity & 125 & $\mathrm{rad} / \mathrm{s}$ \\
\hline Motor M & Displacement volume & $150 \times 10^{-6}$ & $\mathrm{~m}^{3} / \mathrm{rev}$ \\
\hline Flywheel FW & Moment of inertia & 50 & $\mathrm{kgm}^{2}$ \\
& Mass & 100 & $\mathrm{~kg}$ \\
\hline On/Off valves & Spool diameter & 0.01 & $\mathrm{~m}$ \\
& Maximum spool displacement & 0.01 & $\mathrm{~m}$ \\
& Time-lag & 0.1 & $\mathrm{~s}$ \\
\hline Servo valves & Spool diameter & 0.01 & $\mathrm{~m}$ \\
& Maximum spool displacement & 0.001 & $\mathrm{~m}$ \\
& Time-lag & 0.015 & $\mathrm{~s}$ \\
\hline Relief valve & Cracking pressure & $6 \times 10^{6}$ & $\mathrm{~Pa}$ \\
& Fully open pressure & $6.5 \times 10^{6}$ & $\mathrm{~Pa}$ \\
\hline
\end{tabular}

Figures 2 and 3 show the block diagram of a conventional water hydraulic servo motor system and an independent metering system for water hydraulic motor, respectively, with the main components are as follows. They both use a fixed displacement pump $\mathrm{P}$ connected to an engine E. A pressure relief valve RV is assembled on the output port of the hydraulic pump P. A hydraulic motor $\mathrm{M}$ with flywheel FW is driven by a four-way, three-position flow control valve $\mathrm{FV}_{3}$ (servo valve) in the conventional system and two three-way three-position flow control valves in the independent metering system. For easy comparison, the characteristics of the engine E, pump P, hydraulic motor M, and flywheel FW were chosen to be the same as in the proposed system. The two systems were considered for comparison with the proposed system mainly in terms of energy-saving performance. Table 1 shows the specifications of the main devices used in simulation. In this research, the temperature of the system was considered to be the constant room temperature of $25^{\circ} \mathrm{C}$, water was considered to be incompressible fluid and external leakage was ignored.

\subsection{Control system design}

The proposed system (shown in Fig. 1) is designed to improve energy efficiency. The hydraulic transmission consists of two On/Off valves $\mathrm{SV}_{1}$ and $\mathrm{SV}_{2}$ used for changing the rotational direction (clockwise or anti-clockwise cycles abbreviated as CW and ACW, respectively) of the flywheel FW. The third On/Off valve SV is an unload valve. It is opened fully during the deceleration and idle phases and closed during the acceleration and constant phases. Two flow control valves $\mathrm{FV}_{1}$ and $\mathrm{FV}_{2}$ are used for controlling the flywheel to track the reference. The control algorithm for these flow control valves are modified depending on whether the direction of rotation of the flywheel FW is CW or ACW and whether the system is in the acceleration, constant, deceleration, or idle phase.

Figure 4 shows the schematic diagram of the control system 1 for the proposed system. There are two independent control circuits for the On/Off valves and flow control valves. The On/Off valves mode switch and FV 1 and FV 2 mode switch are based on the reference signal for choosing the working states for each valve. The detail is shown in Fig. 5. The unload On/Off valve SV is opened only during the idle and deceleration phases for reducing the supply pressure and closed during the other phases.

The clockwise motion of the flywheel FW is considered first. The On/Off valve $\mathrm{SV}_{2}$ was always closed. During the acceleration and constant phases, the On/Off valve $\mathrm{SV}_{1}$ was opened because the hydraulic motor $\mathrm{M}$ required high pressure fluid in the chamber A. The velocity of the hydraulic motor $\mathrm{M}$ in these phases was controlled by the flow control valve $\mathrm{FV}_{1}$. Note that in Fig. 5, PID represents the proportional-integral-derivative controller. During these phases, the fluid control valve $\mathrm{FV}_{2}$ was opened fully for reducing the meter-out pressure to nearly the atmospheric pressure. During the deceleration and idle phases, the On/Off valve $\mathrm{SV}_{1}$ was closed because the hydraulic motor $\mathrm{M}$ did not require the supply of energy. The fluid control valve $\mathrm{FV}_{1}$ was closed as well. The velocity of the flywheel was controlled via the meter-out orifice - the fluid control valve $\mathrm{FV}_{2}$. The hydraulic motor $\mathrm{M}$ sucked water from the reservoir via the check valve $\mathrm{CV}_{1}$.

During the anticlockwise rotation of the flywheel, the control logic for these valves were the same as that during clockwise rotation with the only difference that the functions of the On/Off valves $\mathrm{SV}_{1}$ and $\mathrm{SV}_{2}$ and flow control valves $\mathrm{FV}_{1}$ and $\mathrm{FV}_{2}$ were reversed simultaneously. The detail can be observed in Fig. 5.

The control logics of the SV mode switches as shown in Figs. 2 and 3 for the unload On/Off valve SV in the conventional system and the independent metering system are similar to the control logic for the On/Off valve SV in the proposed system, which is shown in Fig. 5, with the only difference that the On/Off valve SV in the conventional system is closed in the deceleration phase because the conventional system still requires supply energy during this phase. The 


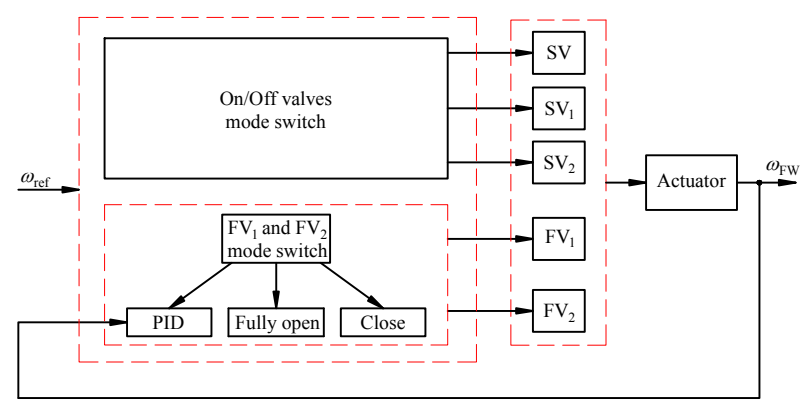

Fig. 4 Schematic diagram of control system 1.

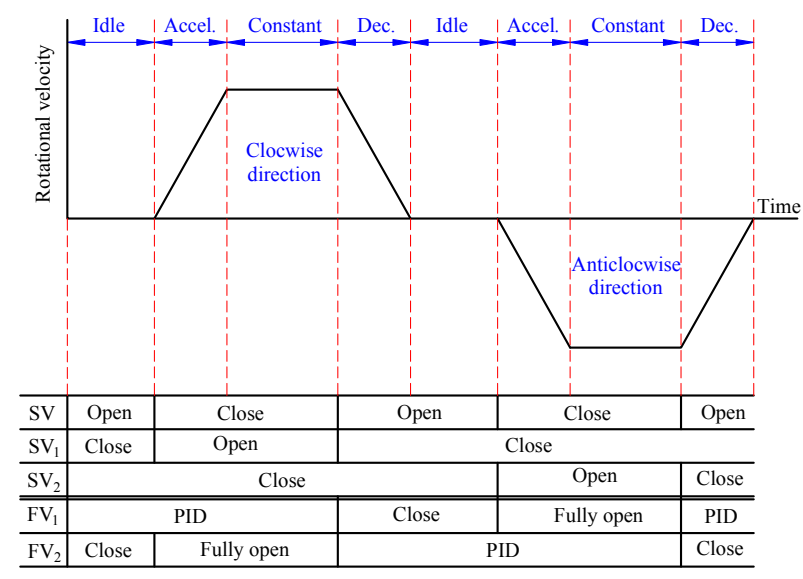

Fig. 5 Control modes for On/Off valves and flow control valves in the proposed system.

controller 3 shown in Fig. 2 for the servo valve in the conventional system is also a PID controller, and the logics for the $\mathrm{FV}_{4}$ and $\mathrm{FV}_{5}$ mode switch for the meter-in and meter-out flow control valves in Fig. 3 are same as those for the valves $\mathrm{FV}_{1}$ and $\mathrm{FV}_{2}$ in the conventional system shown in Fig. 5. The terminology "Fully open" was understood to mean that the valve was completely opened to release the water to the reservoir, the terminology "Close" was replaced by the neutral state of the servo valve. During acceleration and constant phases, and the terminology "PID" means the three-way, three-position valve receives PID control signal and operates at the left position for supplying high pressure water from the pump P to the hydraulic motor M. During deceleration and idle phases, the terminology "PID" means three-way, three-position valve receives PID control signal and operates at the right position for releasing the fluid from the hydraulic motor $\mathrm{M}$ to the reservoir.

\subsection{Energy saving analysis}

The proposed system and conventional system adopted the same hydraulic motor M, flywheel FW, supply response consisting of the engine E, and pump P. Thus, the energy efficiency improvement in the proposed system comes solely from the hydraulic transmission.

Energy consumption for a hydraulic system is calculated as follows:

$$
E_{s}=\int_{t_{s}}^{t_{e}} P_{s} Q_{s} d t=\int_{t_{s}}^{t_{e}}\left(P_{L}+\Delta P\right)\left(Q_{L}+\Delta Q\right) d t=E_{r}+\Delta E_{P}+\Delta E_{Q}
$$

where $E_{s}, E_{r}, \Delta E_{P}$, and $\Delta E_{Q}$ respectively represent the hydraulic supply energy, required energy, and energy losses due to surplus pressure and flow rate in the hydraulic transmission used for a certain task from $t_{s}$ to $t_{e}$. These are derived in Eqs. (2), (3), (4). $P_{s}, P_{L}$, and $\Delta P$ are the supply pressure, load pressure, and surplus pressure, respectively; $Q_{s}, Q_{L}, \Delta Q$ are the flow rates of the pump, load, and surplus flow rate, respectively.

$$
\begin{aligned}
& E_{r}=\int_{t_{s}}^{t_{e}} P_{L} Q_{L} d t \\
& \Delta E_{P}=\int_{t_{s}}^{t_{e}} \Delta P Q_{L} d t \\
& \Delta E_{Q}=\int_{t_{s}}^{t_{e}} P_{s} \Delta Q d t
\end{aligned}
$$

It is obvious that there may be two methods to reduce energy consumption, which are as follows: Reduce the surplus pressure $\Delta P$ and surplus flow rate $\Delta Q$, corresponding to reduce the supply pressure $P_{s}$ and supply flow rate $Q_{s}$.

Unlike oil hydraulics that predominantly uses load-sensing technology for reducing the surplus pressure, the recent technology of water hydraulic systems uses only a relief valve for setting the supply pressure for all working periods as shown in Fig. 2. This is because there is no water hydraulic variable displacement pump available in the market. Neglecting fluid compressibility, the supply flow rate depends only on the drive pattern of the flywheel FW and the displacement of the hydraulic motor M. Reducing the supply pressure is, therefore, the most important method for saving energy in water hydraulic transmission. 
In the conventional system that uses servo or proportional valve or even an independent metering system with a fixed displacement pump, a constant supply pressure value was set up throughout a task. Normally, the supply pressure is based on the load pressure during the acceleration phase, which requires the highest supply pressure. During the other phases i.e., the constant and deceleration phases, which require less supply pressure, the available surplus pressure becomes significantly larger than required. During the deceleration phase of the independent metering system, no energy supply is required. This system can use the unload valve during the deceleration phase for reducing the supply energy.

In the proposed system, the supply water from the pump could flow to the hydraulic motor directly only through an On/Off valve. The pressure drop was effected only by the hoses and the On/Off valves in fully open state. It was a very small value. It is assumed that load-sensing technology with a water hydraulic variable displacement pump can be used in the conventional system and independent metering system. The pump pressure margins are set to overcome the losses in the hoses and the orifices of the flow control valve (proportional or servo valve). These losses are bigger than that of proposed system because of the huge losses through these orifices. More detail analysis for energy loss in each system could be found in subsection 5.2.

\section{Mathematical model}

\subsection{Flow control valve}

In this simulation, the behavior of the two-way, two-port flow control valves $\mathrm{FV}_{1}, \mathrm{FV}_{2}$, and three-way, three-port valves $\mathrm{FV}_{4}, \mathrm{FV}_{5}$ is considered to be similar to that of the three-way, four-port servo valve $\mathrm{FV}_{3}$ after removing two ports and one position and one port, respectively. The mathematical model of the servo valve $\mathrm{FV}_{3}$ (as well as the valves $\mathrm{FV}_{1}$, $\mathrm{FV}_{2}, \mathrm{FV}_{4}, \mathrm{FV}_{5}$ ) is as follows.

The spool valve displacement $x_{v}(t)$ is related to the control input $u(t)$ by a first-order system given by

$$
\tau_{v} \dot{x}_{v}(t)+x_{v}(t)=k_{v} u(t)
$$

where $\tau_{v}$ and $k_{v}$ are the time constant and gain of the servo valve dynamics, respectively.

In addition, to minimize the valve leakage losses which increase with wear and tear of the spool and valve body, the spool is designed to have overlap so that for a range of the spool positions $x_{v}$, there is no fluid flow. This leads to the dead-zone between the spool position $x_{v}$ and the effective spool position $x_{v e}$ and is shown in Fig. 6. The dead-zone nonlinearity of the spool position with left and right break-points $\left(b_{l}<0\right.$ and $b_{r}>0$, respectively) as shown in Fig. 6 can be described by

$$
x_{v e}= \begin{cases}x_{v}-b_{r}, & \text { if } x_{v} \geq b_{r} \\ 0, & \text { if } b_{l}<x_{v}<b_{r} \\ x_{v}-b_{l}, & \text { if } x_{v} \leq b_{l}\end{cases}
$$

The leakage of the servo valve is quite small and it is neglected in this study. Hence, the servo valve flows $Q_{A}$ and $Q_{B}$ can be calculated as follows (Yao et al., 2000):

$$
\begin{aligned}
& Q_{A}= \begin{cases}k_{q A} x_{v e} \sqrt{\left|P_{s}-P_{A}\right|}, & \text { for } x_{v e} \geq 0 \\
k_{q A} x_{v e} \sqrt{\left|P_{A}-P_{r}\right|}, & \text { for } x_{v e}<0\end{cases} \\
& Q_{B}= \begin{cases}k_{q B} x_{v e} \sqrt{\left|P_{B}-P_{r}\right|}, & \text { for } x_{v e} \geq 0 \\
k_{q B} x_{v e} \sqrt{\left|P_{s}-P_{B}\right|}, & \text { for } x_{v e}<0\end{cases}
\end{aligned}
$$

where $P_{A}, P_{B}, P_{s}$, and $P_{r}$ are the pressures of the two chambers of the motor, the supply pressure, and the reservoir pressure, respectively. $k_{q A}$ and $k_{q B}$ are the flow gain coefficients of the servo valve.

\subsection{On/Off valve}

The flow rate $Q_{\text {On/Off }}$ through the On/Off valve can be calculated by the orifice equation as follows (Jelali and Kroll, 2003):

$$
Q_{O n / O f f}=\alpha_{d} A_{O n / O f f} \sqrt{\frac{2}{\rho} \Delta P_{O n / O f f}}
$$




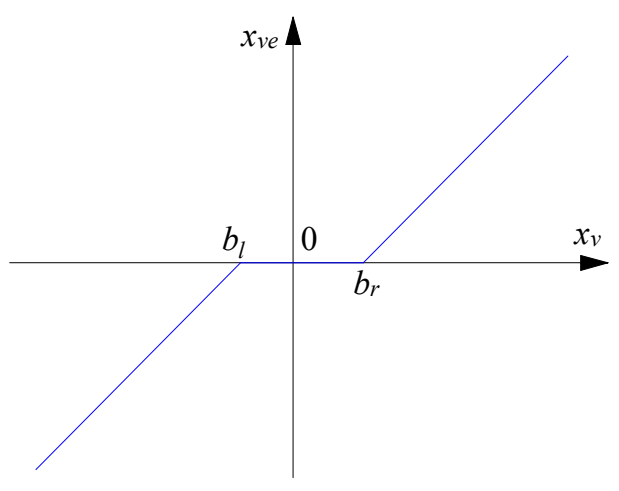

Fig. 6 Dead-zone characteristics of servo valve.

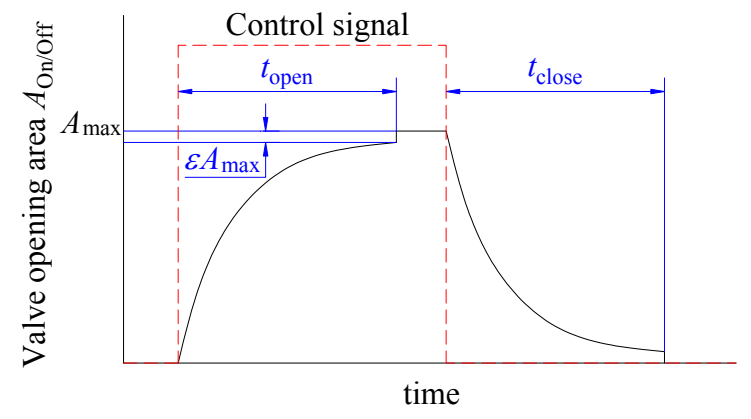

Fig. 7 Characteristics of opening area of On/Off valve.

where $\alpha_{d}$ is the discharge coefficient, $A_{O n / O f f}$ is the opening area of the On/Off valve, $\rho$ is the mass density of water, and $\Delta P_{O n / O f f}$ is the pressure difference between the input and output ports of the On/Off valve.

Figure 7 shows the characteristics of the opening area of On/Off valve. There exist time delays for both opening and closing processes, $t_{\text {open }}$ and $t_{\text {close }}$, respectively. These were approximated as the step response of a first order system. Based on the catalog and analysis from experimental data on the On/Off valve, the values of $t_{\text {open }}$ and $t_{\text {close }}$ were chosen to be $0.04 \mathrm{~s}$ and $0.1 \mathrm{~s}$, respectively for the simulation.

\subsection{Hydraulic motor}

In this system, the hydraulic motor is a two-way axial piston motor. Newton's second law is applied to obtain the torque balance equation for the motor,

$$
I_{F W} \dot{\omega}+T_{f}=T_{m}
$$

where $I_{F W}$ is the moment of inertia of the flywheel, $\omega$ the angular velocity of the flywheel, $T_{f}$ the friction torque, and $T_{m}$ the torque of the motor. The friction torque can be expressed by (Jelali and Kroll, 2003)

$$
T_{f}=T_{v} \omega+\operatorname{sign}(\omega)\left[T_{c 0}+T_{s 0} \exp \left(-\frac{|\omega|}{c_{s}}\right)\right]
$$

where $T_{v}, T_{c 0}, T_{s 0}$, and $c_{s}$ are the coefficients for viscous friction, Coulomb friction, and static friction, respectively.

The torque of the motor can be expressed by

$$
T_{m}=\frac{D_{m}}{2 \pi}\left(P_{A}-P_{B}\right)
$$

where $D_{m}$ is the displacement volume of the motor.

Based on the continuity equation, the pressure dynamics in the motor chambers are given by

$$
\begin{aligned}
& \dot{P}_{A}=\frac{E}{V_{0}}\left[Q_{A}-\frac{D_{M}}{2 \pi} \omega-C_{L i}\left(P_{A}-P_{B}\right)\right] \\
& \dot{P}_{B}=\frac{E}{V_{0}}\left[-Q_{B}+\frac{D_{M}}{2 \pi} \omega+C_{L i}\left(P_{A}-P_{B}\right)\right]
\end{aligned}
$$

where $E$ is bulk modulus of water assumed to be constant value and $C_{L i}$ the internal leakage flow coefficient. Both chamber volumes have been assumed to be equal to $V_{0}$.

\section{Velocity Response}

The main contribution of this study is the improvement in the energy efficiency of the water hydraulic transmission used in a water hydraulic motor system. However, the behavior of the actuator is a very important factor in such a system and needs to be considered first.

The control tracking performance of the proposed system is compared with those of the conventional servo motor system and the independent metering system. The three systems used the same reference trajectory, which is shown 


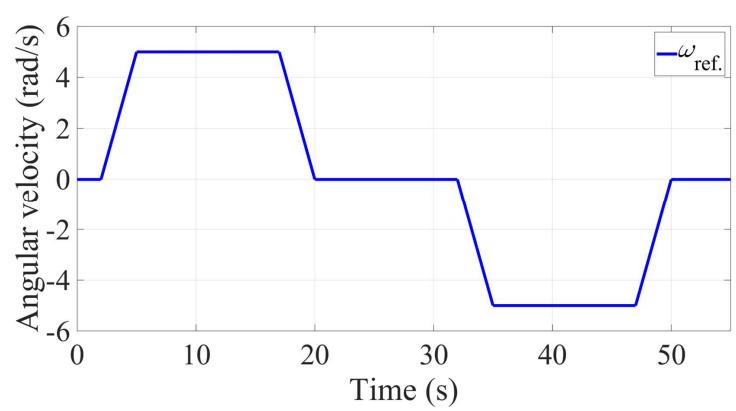

Fig. 8 Reference trajectory.

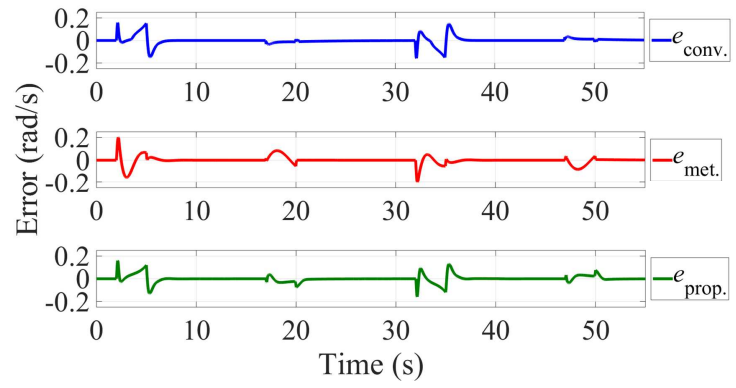

Fig. 9 Comparison of tracking performance.

Table 2 Comparison of tracking errors.

\begin{tabular}{l|c|c|c}
\hline Systems & $\|e\|_{1}$ & $\|e\|_{2}$ & $\|e\|_{\infty}$ \\
\hline Conventional system & 0.788 & 0.061 & 0.160 \\
\hline Independent metering system & 0.747 & 0.059 & 0.201 \\
\hline Proposed system & 0.776 & 0.050 & 0.161 \\
\hline
\end{tabular}

in Fig. 8. The reference consists of two cycles - clockwise direction and anticlockwise direction - which are divided into 4 phases: idle, acceleration, constant, and deceleration. The control algorithm of these systems was introduced in subsection 2.2 .

The tracking performances of the three systems for the same desired motion trajectory shown in Fig. 8 are plotted in Fig. 9. All three systems show excellent tracking performance. A more detailed comparison of the tracking errors $(e(t))$ is shown in Table 2, and the criteria for the comparison are defined in Eqs. (15), (16), and (17) (Liu and Yao, 2008). This table indicates that the control performance of the proposed system is at least equal to that achieved with the use of the conventional servo motor system or independent metering system. The time-lag of the On/Off valves $S V, S_{1}$, and $S_{2}$ affected to the system much when the system changed the state from ideal phase to acceleration phase (at 2 second and 32 second). If faster On/Off valves are utilized in the proposed system, better control performance can be achieved.

$$
\begin{aligned}
& \|e\|_{1}=\int_{0}^{55}|e(t)| d t \\
& \|e\|_{2}=\int_{0}^{55} e^{2}(t) d t \\
& \|e\|_{\infty}=\max _{0 \leq t \leq 55}|e(t)|
\end{aligned}
$$

\section{Energy performance}

\subsection{Energy efficiency}

Figure 10 shows the load pressure, which is defined in Eq. (18), in the proposed system $\left(P_{\mathrm{L} . \text { prop. }}\right)$, supply pressures in the conventional servo motor system $\left(P_{\text {s.conv. }}\right)$, independent metering system $\left(P_{\text {s.met. }}\right)$, and proposed system $\left(P_{\text {s.prop. }}\right)$. Figure 11 presents the supply flow rates, which are the same in the three systems and denoted by $Q_{s}$, flow rates at the

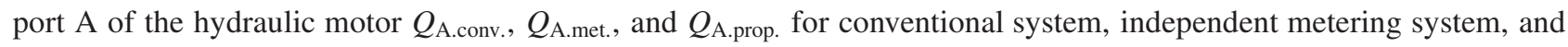
proposed system, respectively.

$$
P_{L . i}=\left|P_{A . i}-P_{B . i}\right|
$$

where $P_{L . i}, P_{A . i}$, and $P_{B . i}$ are the load pressure and pressures at the ports A and B of the hydraulic motor M, respectively; $i$ denotes the conventional system, independent metering system, or proposed system.

The supply energy of each system depends on the supply pressure and supply flow rate as shown in Eqs. (19-21). The supply flow rates in all three systems, which were provided by the same fixed displacement pump with the same rotational velocity, were equal. Hence, the supply energies depend only on the supply pressure as shown in Fig. 10.

In the conventional servo motor system, the supply pressure was adjusted via the relief valve. Thus, it had the same value during all the phases including acceleration, constant, and deceleration; this value was based on the required supply pressure during the acceleration phase, which was the highest among all the phases. In the independent metering 


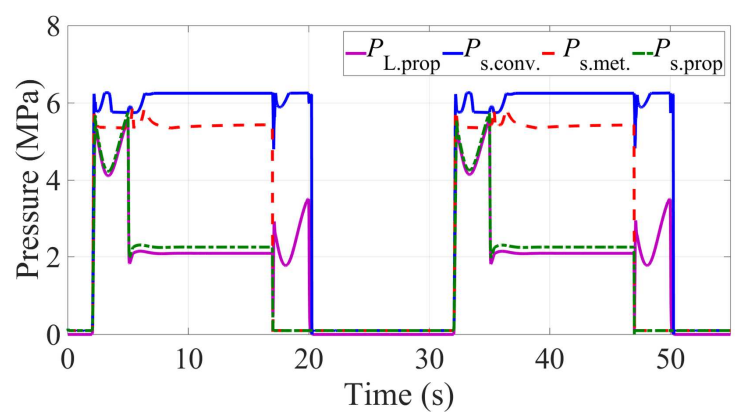

Fig. 10 Load pressure in proposed system and supply pressures in three systems.

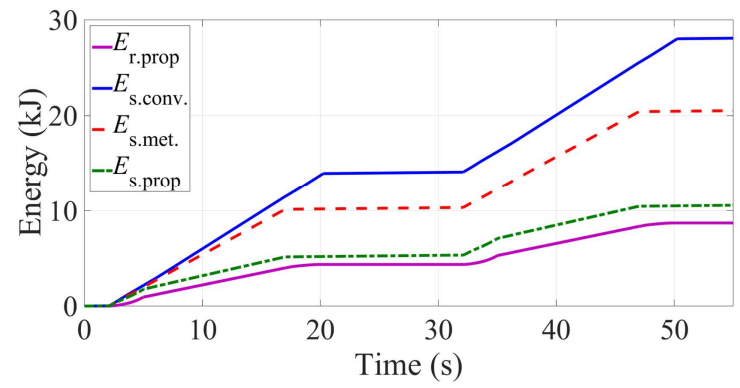

Fig. 12 Required energy in the proposed system and supply energies in the three systems.

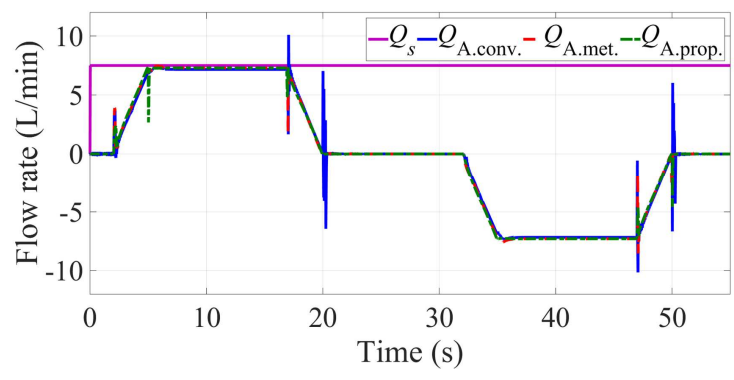

Fig. 11 Pump and motor flow rates in three systems.

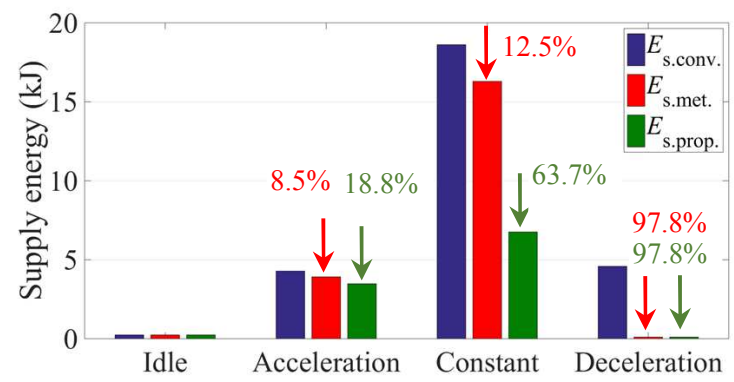

Fig. 13 Comparison of supply energies during the 4 phases.

system also, the supply pressure during the acceleration and constant phases was set up via the relief valve based on the highest required supply pressure, which was during the acceleration phase. During the acceleration phase, the pressure at the meter-out point of the independent metering system, which was nearly equal to the atmospheric pressure, was much smaller than that in the conventional system; the supply pressure in the independent metering system was set up at a value smaller than that in the conventional system.

The biggest difference in supply pressure among the three systems was during the constant and deceleration phases. During the deceleration phase, the independent metering system and the proposed system required no supply pressure for reducing the velocity of the flywheel. The unload valves in the two systems were used for reducing the supply pressure to the value close to zero; while the supply pressure in the conventional system remained at a value equal to that during the acceleration and constant phases. In the constant (velocity) phase, the supply pressure in the independent metering system was smaller than that in the conventional system; the supply pressure difference between these two systems was due to the pressure at the meter-out point as mentioned above. The supply pressure in the proposed system was significantly reduced and was only slightly higher than the load pressure. It is because the supply pressure from the pump P can be transmitted to the hydraulic motor $\mathrm{M}$ with negligible losses throughout the hoses and On/Off valve.

Figure 12 shows the required energy for the hydraulic motor $\mathrm{M}$ in the proposed system, which is almost equal to that in the conventional system and independent metering system as well as the supply energy in all the three systems. It is easy to realize that by applying the proposed system, the energy consumption has been reduced significantly and the gap between the supply energy and the required energy, which denotes the energy loss, was very small. The energy efficiency of all the three systems can be seen in Table 3. The proposed system can improve the energy efficiency of the hydraulic transmission to nearly two times and three times that of the independent metering system and conventional system, respectively.

Figure 13 shows the energy consumption improvement of the proposed system during each phase in detail. All the three systems consumed the same energy in the ideal phase because they used the same unload On/Off valve SV for

Table 3 Comparison of energy efficiencies.

\begin{tabular}{l|c|c|c}
\hline Systems & $\begin{array}{c}E_{r} \\
(\mathrm{~kJ})\end{array}$ & $\begin{array}{c}E_{s} \\
(\mathrm{~kJ})\end{array}$ & $\begin{array}{c}\eta \\
(\%)\end{array}$ \\
\hline Conventional system & 8.539 & 28.085 & 30.40 \\
\hline Independent metering system & 8.685 & 20.525 & 42.31 \\
\hline Proposed system & 8.699 & 10.552 & 82.44 \\
\hline
\end{tabular}




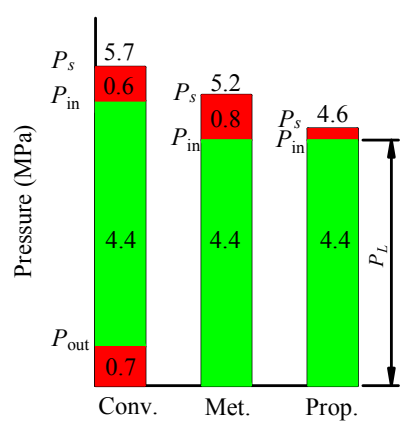

(a) Acceleration phase

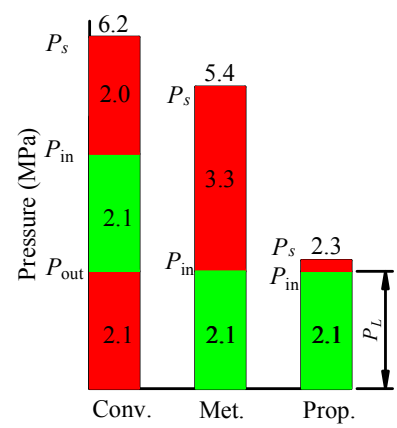

(b) Constant phase

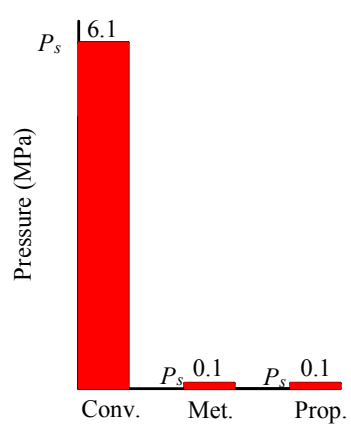

(c) Deceleration phase

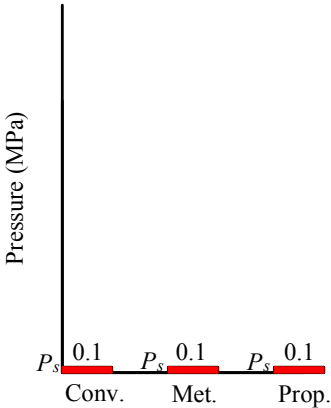

(d) Idle phase

Fig. 14 Supply pressure and pressures at inlet port and outlet port of hydraulic motor for conventional system (Conv.), independent metering system (Met.), and proposed system (Prop.).

reducing the supply pressure throughout this phase. The reductions in the independent metering system and proposed system when compared to the conventional system are $8.5 \%$ and $18.8 \%$ during the acceleration phase, $12.5 \%$ and $63.7 \%$ during the constant (velocity) phase, and $97.8 \%$ and $97.8 \%$ for the deceleration phase, respectively.

\subsection{Energy loss analysis}

Figure 14 shows the supply pressure $\left(P_{s}\right)$ and pressures at the input and output ports $\left(P_{\text {in }}\right.$ and $\left.P_{\text {out }}\right)$ of the hydraulic motors for all the phases - acceleration, constant, deceleration, and idle (Figs. 14 (a), (b), (c), (d), respectively) - for the conventional system, independent metering system, and proposed system with fixed displacement pump. Note that the pressures of each phase are the average values. Contrary to the conventional system and metering system, in the constant (velocity) phase, during which the supply pressure level is equal to that during the acceleration phase, the supply pressure in the proposed system is much smaller for the small pressure drop only due to the piping loss and loss throughout the On/Off valve, which is a very small value. During the deceleration phase, the independent metering system and proposed system do not need supply energy for braking the flywheel. On the other hand, the conventional system still requires supply energy for this process.

In order to analyze the energy loss in each system in detail, the energy losses through all the devices in the three systems are calculated and introduced as shown in Fig. 15. The largest losses in the conventional servo system were because of the pressure drops at the meter-in and meter-out orifices, which are mechanically linked together, and the surplus flow rate, which was released to the reservoir by the relief valve RV. The other small losses were piping loss and loss in the unload On/Off valve during the idle phase. The energy losses in the conventional system are summarized by the following equations:

$$
E_{\mathrm{s} . \mathrm{conv} .}=\int_{0}^{55} P_{\mathrm{s} . \mathrm{conv} .} Q_{\text {s.conv. }} d t=E_{\mathrm{r} . \mathrm{conv} .}+\Delta E_{\mathrm{RV} . \mathrm{conv} .}+\Delta E_{\text {in.conv. }}+\Delta E_{\text {out.conv. }}+\Delta E_{\mathrm{p} \& \text { u.conv. }}
$$

where $E_{\mathrm{s} . c o n v .}$ and $E_{\mathrm{r} . \mathrm{conv}}$ are the supply energy and required energy in the conventional servo valve transmission, respectively. $P_{\text {s.conv. }}$ and $Q_{\text {s.conv. }}$ are the supply pressure and flow rate. $\Delta E_{\mathrm{RV} \text {.conv. }}$ is the energy loss through the relief valve and

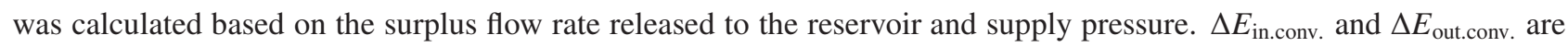
the energy losses at the meter-in and meter-out orifices, respectively, which were calculated based on the pressure drops and the flow rates through the orifices. $\Delta E_{\mathrm{p} \& u . c o n v}$. is the piping loss and loss due to the unload On/Off valve during the idle phase.

In the independent metering system, the biggest loss was at the meter-in orifice, there was almost no loss at the meter-out orifice because it was opened fully during operation. The second biggest loss was because of the surplus flow rate which was released to the reservoir though the relief valve RV. Similar to the conventional system, the hose loss and the loss at the unload valve were considerably small. The energy losses in the independent metering system are given by the following equation:

$$
E_{\text {s.met. }}=\int_{0}^{55} P_{\text {s.met. }} Q_{\text {s.met. }} d t=E_{\text {r.met. }}+\Delta E_{\mathrm{RV} . \text { met. }}+\Delta E_{\text {in.met. }}+\Delta E_{\mathrm{p} \& \text { u.met. }}
$$

where $E_{\mathrm{s} . \mathrm{met}}$ and $E_{\mathrm{r} . \mathrm{met}}$ are the supply energy and required energy in the independent metering system, respectively; $P_{\mathrm{s} \text {.met. }}$ and $Q_{\text {s.met. }}$ are the supply pressure and flow rate, respectively; $\Delta E_{\mathrm{RV} \text {.met. }}$ is the energy loss through the relief valve and was calculated based on the surplus flow rate released to the reservoir and supply pressure; $\Delta E_{\text {in.met. }}$ is the energy losses at the 


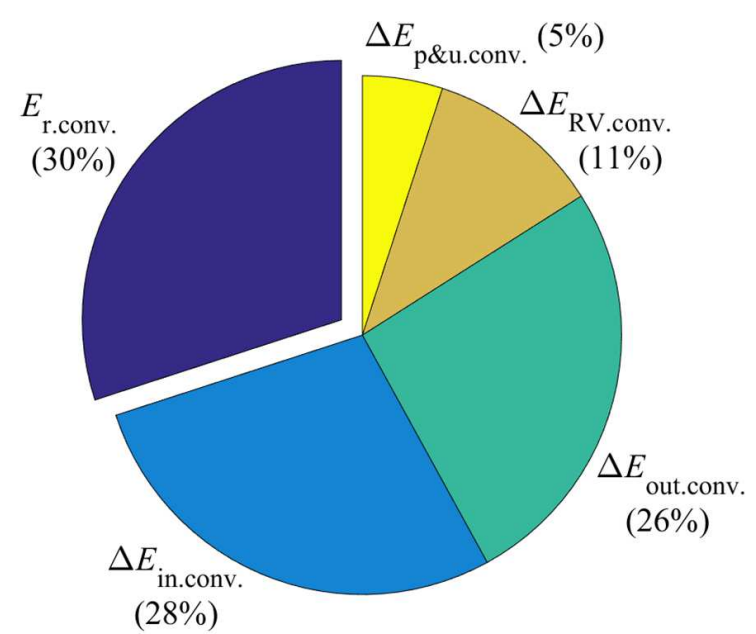

(a)

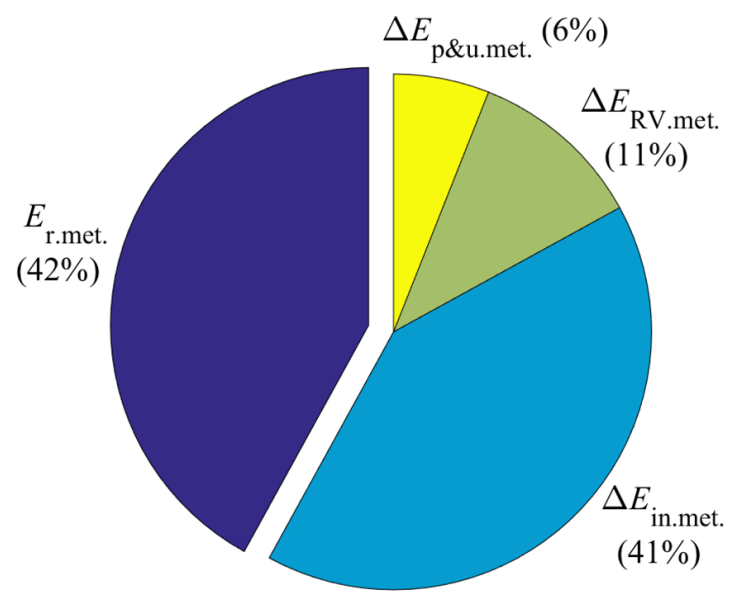

(b)

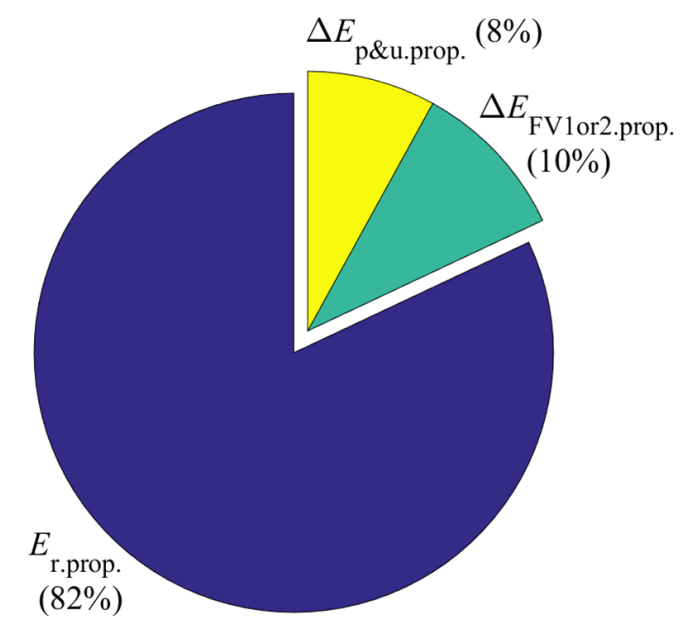

(c)

Fig. 15 Required energy and energy losses in three systems. (a) conventional system, (b) independent metering system, (c) proposed system.

meter-in orifice, which were calculated based on the pressure drops and the flow rates through the orifice; and $\Delta E_{\mathrm{p} \& u . m e t .}$ is the piping loss and loss due to the unload On/Off valve.

In the proposed system, the biggest loss caused by the surplus flow, which was released to the reservoir though the flow control valve $\mathrm{FV}_{1}$ or $\mathrm{FV}_{2}$ when it was used to control the pressure at the input port of the hydraulic motor M. The pressure drop from the pump to the motor, which was because of the hose loss and loss through the On/Off valve, was very small, the other loss was at the unload valves. The energy losses in the proposed system are captured in the following equation. Because this system worked with a supply pressure, which was less than the cracking pressure of the relief valve, there was no energy loss through this valve. It was only used for safety purpose.

$$
E_{\text {s.prop. }}=\int_{0}^{55} P_{\text {s.prop. }} Q_{\text {s.prop. }} d t=E_{\text {r.prop. }}+\Delta E_{\mathrm{FV} 1 \text { or2.prop. }}+\Delta E_{\mathrm{p} \& \text { u.prop. }}
$$

where $E_{\mathrm{s} \text {.prop. }}$ and $E_{\mathrm{r} \text {.prop. }}$ are the supply energy and required energy in the proposed system, respectively; $P_{\text {s.prop. }}$ and $Q_{\text {s.prop. }}$ are the supply pressure and flow rate, respectively; $\Delta E_{\mathrm{FV} 1 \text { or2.prop. }}$ is the energy losses caused by flow control valve $\mathrm{FV}_{1}$ or $\mathrm{FV}_{2}$ depending on the direction of the flywheel when it controlled the pressure at the input port of the hydraulic motor $\mathrm{M}$ by releasing the surplus flow to the tank; and $\Delta E_{\mathrm{p} \& u . p r o p .}$ is the piping loss and loss due to the unload On/Off valve. In this system, the energy loss caused by the On/Off valve $\mathrm{SV}_{1}$ or $\mathrm{SV}_{2}$, which were used for changing the rotational direction of the flywheel, was small and it was considered to be a part of piping loss. 


\section{Conclusions}

A novel water hydraulic transmission aimed at improving the energy efficiency by reducing the surplus pressure was introduced and compared with a conventional servo motor system and an independent metering system. The velocity responses in the proposed system showed the same level as that of the two compared systems.

The main contribution of the proposed system is higher energy efficiency. The proposed system used two two-way, two-position flow control valves for controlling the pressure at the input port of the hydraulic motor, and the surplus flow rate was released to the tank through these valves. With this method, the surplus pressure was minimized only due to the hose and On/Off valve losses. Therefore, the energy efficiency in the proposed transmission increased to nearly two times and three times that of the independent metering system and conventional system, respectively. The energy losses in the three systems were analyzed in detail as well.

Future work will focus on the experiment and comparison with the simulation results. The details will be introduced in the second report.

\section{References}

Ito, K., Control performance comparison of simple adaptive control to water hydraulic servo cylinder system, Proceedings of 19th Mediterranean Conference on Control and Automation, Corfu, Greece (2011), pp.195-200.

Jelali, M. and Kroll, A., Hydraulic servo-systems modelling identification and control (2003), Springer-Verlag London.

Kobayashi W. and Ito K., Development of Gait-training orthosis with water hydraulic McKibben muscle, Proceedings of The 12th International Conference on Fluid Control, Measurements and Visualization, Nara, Japan (2013).

Liu, S. and Yao, B., Coordinate control of energy saving programmable valves, IEEE Transactions on Control Systems Technology, Vol.16, No.1 (2008), pp.34-45.

Merritt, H. E., Hydraulic Control Systems (1967), John Wiley \& Sons.

Minakawa, Y., Yamochi, T. and Mutoh, H., Research on the water hydraulic drive mechanism powered by an accumulator, Proceedings of The 12th International Conference on Fluid Control, Measurements and Visualization, Nara, Japan (2013).

Nielsen B., Controller development for a separate meter-in separate meter-out fluid power valve for mobile applications, Dissertation Aalborg University, Denmark (2005).

Opdenbosch, P., Sadegh, N. and Book, W., Intelligent controls for electro-hydraulic poppet valves, Control Engineering Practice, Vol.21, No.6 (2013), pp.789-796.

Pham, P. N., Ito, K. and Ikeo, S., The application of simple adaptive control for simulated water hydraulic servo motor system, Proceedings of The 2013 IEEE International Conference on Industrial Technology, Cape Town, South Africa (2013), pp.204-209.

Plummer, A. R. and Vaughan, N. D., Robust adaptive control for hydraulic servo systems, Journal of Dynamic Systems, Measurement, and Control - Transaction of the ASME, Vol.118, No. 2 (1996), pp.237-244.

Sato, I., Commercialization of food processing machinery equipped with ADS, Proceedings of JFPS Autumn Seminar Current State of Industrial Use of Aqua Drive System (2015), pp.17-22 (in Japanese).

Stelson, K. A., Saving the world's energy with fluid power, Proceedings of The 8th JFPS International Symposium on Fluid Power, Okinawa, Japan (2011), pp.1-7.

Tsao, T. C. and Tomizuka, M., Robust adaptive and repetitive digital tracking control and application to a hydraulic servo for noncircular machining, Journal of Dynamic Systems, Measurement, and Control - Transaction of the ASME, Vol.116, No.1 (1994), pp.24-32.

Wang, T. and Wang, Q., An energy-saving pressure-compensated hydraulic system with electrical approach, IEEE/ASME Transactions on Mechatronics, Vol.19, No.2 (2014), pp.570-578.

Xu, B., Ding, R., Zhang, J., Cheng, M. and Sun, T., Pump/valves coordinate control of the independent metering system for mobile machinery, Automation in Construction, Vol.57 (2015), pp.98-111.

Yao, B., Bu, F., Reedy, J. and Chiu, G. T. C., Adaptive robust motion control of single-rod hydraulic actuators: Theory and experiments, IEEE/ASME Transactions on Mechatronics, Vol.5, No.1 (2000), pp.79-91.

Yao, B. and Liu, S., Energy-saving control of hydraulic systems with novel programmable valve, Proceedings of The 4th World Congress on Intelligent Control and Automation, IEEE Press, Shanghai, China, Vol.4 (2002), pp.3219-3223.

Yin, F. L., Nie, S. L. and Ruan J., Research on the reliability of sliding bearing support in a swash-plate type axial piston 
Pham and Ito, Journal of Advanced Mechanical Design, Systems, and Manufacturing, Vol.10, No.4 (2016)

water hydraulic pump, Proceedings of International Conference on Fluid Power and Mechatronics, Beijing, China (2011), pp.282-286.

Yoshida, F. and Miyakawa, S., Effect of design parameters on stability of water hydraulic proportional control valves, Proceedings of The 12th International Conference on Fluid Control, Measurements and Visualization, Nara, Japan (2013).

Yoshida, F., Introduction and application examples of control valve for ADS, Proceedings of JFPS Autumn Seminar Current State of Industrial Use of Aqua Drive System (2015), pp.25-28 (in Japanese). 